$\begin{array}{ll}\phi & =\text { fugacity coefficient } \\ \omega & =\text { acentric factor }\end{array}$

$[-]$

$\langle$ Subscripts $\rangle$

$\begin{array}{ll}C M & =\text { pseudocritical property } \\ c & =\text { critical property } \\ M & =\text { mixture property } \\ r & =\text { reduced property } \\ i, j, k & =\text { component } i, j, k\end{array}$

〈Superscript >

(i) $\quad=$ component $i$

\section{Literature Cited}

1) Arai, K., H. Inomata and S. Saito: J. Chem. Eng. Japan, 15, 1 (1982).
2) Bender, E.: 5th International Congress of Chemical Engineering, CHISA 75, Section F2.25 (1975).

3) Joffe, J.: Ind. Eng. Chem., Fundam., 15, 298 (1976).

4) Lee, B. I. and M. G. Kesler: AIChE J., 21, 510 (1975).

5) Nishiumi, H. and S. Saito: J. Chem. Eng. Japan, 8, 356 (1975).

6) Plöcker, U., H. Knapp and J. Prausnitz: Ind. Eng. Chem., Process Des. Dev., 17, 324 (1978).

7) Reamer, H. H., R. H. Olds, B. H. Sage and W. N. Lacey: Ind. Eng. Chem., 34, 1536 (1942).

8) Soave, G.: Chem. Eng. Sci., 27, 1197 (1972).

9) Teja, A. S. and P. Rice: Chem. Eng. Sci., 36, 1 (1981).

10) Van Ness, H. C.: AIChE J., 1, 100 (1955).

11) Wiese, H. C., H. H. Reamer and B. H. Sage: J. Chem. Eng. Data, 15, $75(1970)$

\title{
LYSIS RATES OF FIBRIN CLOT BY PLASMIN
}

\author{
EIzo SADA, SHigeo KATOH AND SHUNiChIRo HARA \\ Department of Chemical Engineering, Kyoto University, Kyoto 606
}

Key Words: Medical Chemical Engineering, Biochemical Engineering, Enzyme Reaction, Adsorption, Fibrinolysis, Plasmin

\section{Introduction}

Under normal conditions a homeostatic balance between blood coagulation and fibrinolysis maintains fluidity in the vascular system. The conversion of fibrinogen to fibrin by thrombin makes a thrombus, as shown in Fig. 1. In the fibrinolytic system fibrin is hydrolyzed by the proteolytic enzyme plasmin, which is activated from plasminogen by plasmin activators. Therapeutic enhancement of the fibrinolytic system by these activators, such as urokinase and streptokinase, has been attempted for treatment of many pathological disorders caused by enhanced coagulability. Recent biochemical studies ${ }^{1)}$ of the plasminogen molecule elucidated that plasmin and plasminogen have the lysine-binding site and interact with fibrin and antiplasmin through it. The enzymatic lysis mechanism of solids such as fibrin is still uncertain. So it is interesting to study the effect of the interaction between plasmin or plasminogen and fibrin on the lysis rate. The present work was undertaken to measure the rates of fibrinolysis by plasmin and plasminogen-urokinase and to study the mechanism of fibrinolysis.

Received October 24, 1984. Correspondence concerning this article should be addressed to E. Sada.

\section{Materials and Methods}

Bovine serum fibrinogen (Nakarai Chemicals Co.) was made plasminogen-free by a lysine-Sepharose $4 \mathrm{~B}$ affinity column. Plasminogen and plasmin, which had the lysine-binding site, in bovine fibrinogen were selectively adsorbed in this column. The fibrinogen was fluoro-labelled by fluorescamine.

Bovine thrombin (587 NIH units/mg-protein, Sigma Chemicals Co.) was used to clot fibrinogen. Porcine plasmin and plasminogen (2.7 and 1.7 units/mg-protein, respectively, Sigma Chemicals Co.) were used and their activities were assayed by hydrolysis of casein. One unit is defined as $\Delta A_{280 \mathrm{~nm}}^{1 \mathrm{~cm}}=1.0$ for perchloric acid soluble products in $20 \mathrm{~min}$ at $\mathrm{pH}$ 7.5 and $37^{\circ} \mathrm{C}$. Plasminogen was activated by use of urokinase (Green Cross Co.).

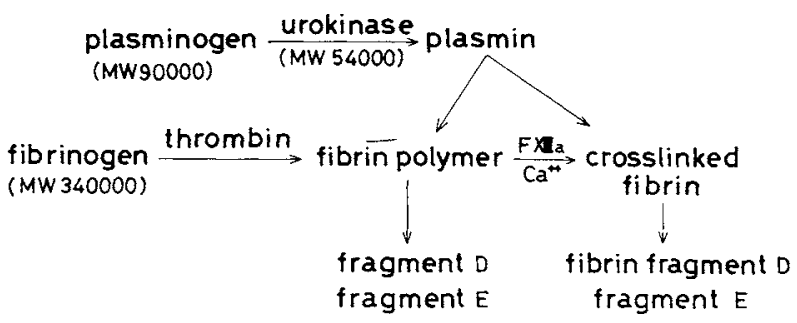

Fig. 1. Scheme of fibrinolysis. 

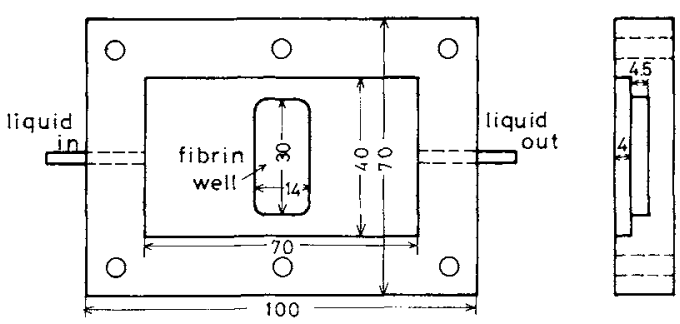

Fig. 2. Details of lysis cell.

Figure 2 shows the details of the cell used to measure the lysis rate. An acrylic resin plate had a rectangular recessed portion, at the center of which was a fibrin well. A fibrinogen solution (0.6$1.8 \mathrm{mg} / \mathrm{cm}^{3}$ in Owren's Veronal buffer, $\mathrm{pH} 7.35$ ) was labelled by adding $0.05 \mathrm{~cm}^{3}$ of an acetone solution of fluorescamine $\left(0.6 \mathrm{mg} / \mathrm{cm}^{3}\right)$ into $2 \mathrm{~cm}^{3}$ and then $1.7 \mathrm{~cm}^{3}$ of the labelled solution was coagulated with $0.1 \mathrm{~cm}^{3}$ of a thrombin solution (100 NIH units $/ \mathrm{cm}^{3}$ ) in the well flush with the surface of the rectangular recessed portion. After washing the surface of the fibrin clot in the well with the buffer, $24 \mathrm{~cm}^{3}$ of a plasmin solution was circulated through the cell at a constant flow rate $\left(3-10 \mathrm{~cm}^{3} / \mathrm{min}\right)$ and the intensity of fluorescence (excitation at $390 \mathrm{~nm}$ and measurement at $475 \mathrm{~nm}$ ) of the circulating solution was continuously measured by a fluorometer (Gilson Model 3301). In some runs a plasminogen-urokinase solution or a plasminogen solution was circulated. All measurements were carried out at $37^{\circ} \mathrm{C}$.

\section{Results and Discussion}

The intensity of fluorescence of labelled fibrinogen was constant for at least $3 \mathrm{~h}$ and the clottability of fibrinogen was not affected by addition of the acetone solution of fluorescamine. Adsorption of plasmin on the surface of the acrylic plate was ignored.

An increase in fluorescence was ignored during circulation of the buffer solution without plasmin. With the plasmin solution the intensity of fluorescence increased almost linearly for $40-60 \mathrm{~min}$ from the start of circulation and then the slope of fluorescence increase was reduced. After $2 \mathrm{~h}$ trypsin was added to the plasmin solution and the fibrin clot was degraded to soluble forms. From the initial slope and the final intensity of fluorescence the lysis rate of the fibrin clot can be obtained. In Fig. 3 the lysis rate is plotted against the initial concentration of the plasmin solution. The lysis rate increased linearly at lower concentrations of plasmin and reached a plateau depending on the fibrinogen concentration. The liquid flow rate and the depth of the fibrin well did not affect the lysis rate. This means that the liquid-phase mass transfer resistance can be neglected and that lysis may proceed from the surface of the fibrin clot because of the impenetrability of plasmin into the fibrin clot.

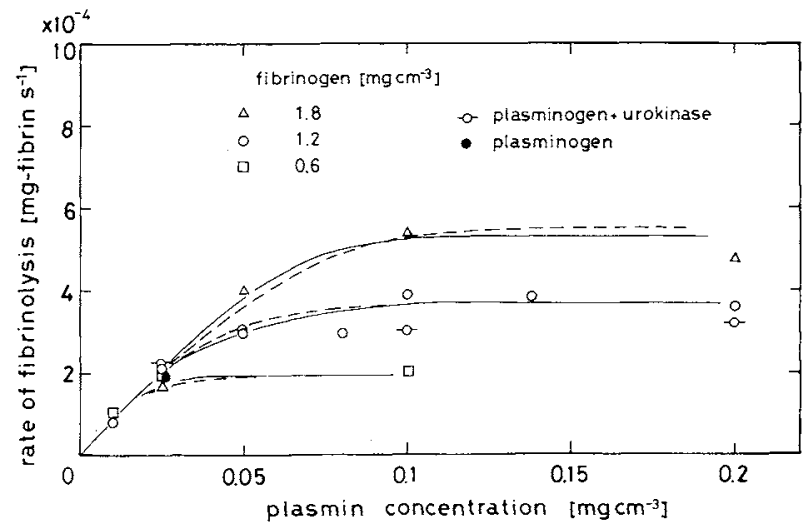

Fig. 3. Lysis rate.

Table 1. Adsorbed plasmin and lysis rate

\begin{tabular}{ccc}
\hline $\begin{array}{c}\text { Fibrinogen concentration } \\
{\left[\mathrm{mg} / \mathrm{cm}^{3}\right]}\end{array}$ & $\begin{array}{c}\text { Adsorbed plasmin } \\
{[\mathrm{mg}]}\end{array}$ & $\begin{array}{c}\text { Lysis rate } \\
{[\mathrm{mg}-\text {-fibrin/s] }}\end{array}$ \\
\hline 0.6 & 0.60 & $2.0 \times 10^{-4}$ \\
1.2 & 1.03 & $3.7 \times 10^{-4}$ \\
1.8 & 1.98 & $5.4 \times 10^{-4}$ \\
\hline
\end{tabular}

The lysis rate at the plateau is directly proportional to the fibrinogen concentration used in preparation of the clot. To investigate the relationship between the lysis rate and the interaction of the lysine-binding site with fibrin, the amount of adsorbed plasmin was measured by assaying the activity of plasmin in the solution before and after $(5 \mathrm{~min})$ the start of circulation. Table 1 shows the lysis rate and the amount of adsorbed plasmin at the plasmin concentration where the lysis rate reaches the plateau value. The lysis rate is nearly proportional to adsorbed plasmin. This result suggests the lysis mechanism of fibrin clot by plasmin adsorbed on the surface of fibrin gel. With the assumption that on fibrin clot the number of the site which interacts with the lysine-binding site of plasmin is proportional to the fibrinogen concentration used, the adsorption isotherm may be expressed by the Langmuir type, $q=k_{1} C /\left(1+k_{2} C\right)$. The lysis rate, which is proportional to the amount of adsorbed plasmin, can be calculated with $k_{2}$ as a parameter. The $k_{2}$ value of $10^{3} \mathrm{~cm}^{3} / \mathrm{mg}$ fits the calculated rates to the experimental data, as shown in Fig. 3 with broken curves. These results suggest that plasmin adsorbed on fibrin clot is available for fibrinolysis, because in vivo fibrinolytic inhibitors such as antiplasmin may interact with the lysine-binding site of free plasmin and inhibit fibrinolysis. The large value of $k_{2}$ indicates that activation of a small fraction of plasminogen may be enough to increase the lysis rate to the maximum value, because the normal ranges of the concentrations of plasminogen and fibrinogen in plasma are $0.1-0.2 \mathrm{mg} / \mathrm{cm}^{3}$ and 1.8 $3.6 \mathrm{mg} / \mathrm{cm}^{3}$, respectively. According to this mech- 
anism of fibrinolysis, a proper dose of plasminogen activators is important, because too great dose might consume plasmin by the interaction with antiplasmin in vivo.

In some runs a solution of plasminogen and urokinase $\left(40\right.$ units $\left./ \mathrm{cm}^{3}\right)$ was circulated through the cell. As shown in Figure 3 the lysis rates were equal to those with the plasmin solutions. A similar result was obtained when a plasminogen solution was circulated on fibrin clot containing 100 units urokinase in it.

In conclusion, plasmin adsorbed on fibrin determines the lysis rate and this mechanism is suitable for effective fibrinolysis in the presence of plasmin inhibitors in vivo.

\section{Nomenclature}

C $=$ fluid-phase concentration

$k_{1} \quad=$ coefficient of Langmuir isotherm

$k_{2}=$ coefficient of Langmuir isotherm

$q=$ adsorbed amount

$$
\begin{array}{r}
{\left[\mathrm{mg} \cdot \mathrm{cm}^{-3}\right]} \\
{[\mathrm{cm}]} \\
{\left[\mathrm{cm}^{3} \cdot \mathrm{mg}^{-1}\right]} \\
{\left[\mathrm{mg} \cdot \mathrm{cm}^{-2}\right]}
\end{array}
$$

\section{Literature Cited}

1) Gaffney, P. J. and S. Balkuv-Ulutin: "Fibrinolysis, Current Fundamental and Clinical Concepts," Academic Press, New York (1978) 